\title{
Global Deletion of Glutathione S-Transferase A4 Exacerbates Developmental Nonalcoholic Steatohepatitis
}

\author{
Martin Ronis, ${ }^{*}$ Kelly Mercer, ${ }^{\dagger \ddagger}$ Bridgette Engi,, Casey Pulliam, * Piotr Zimniak, $"$ Leah Hennings, $"$ Colin Shearn, ** \\ Thomas Badger, ${ }^{\dagger \ddagger}$ and Dennis Petersen**
}

\begin{abstract}
From the Department of Pharmacology and Experimental Therapeutics, * Louisiana State University Health Sciences Center-New Orleans, New Orleans, Louisiana; the Arkansas Children's Nutrition Center ${ }^{\dagger}$ University of Arkansas for Medical Sciences, Little Rock, Arkansas; and the Departments of Pediatrics, ${ }^{\ddagger}$ Laboratory Animal Medicine, ${ }^{\S}$ Pharmacology and Toxicology, " Pathology, " and Pharmaceutical Sciences, ** University of Colorado Anschutz Medical Campus, Aurora, Colorado
\end{abstract}

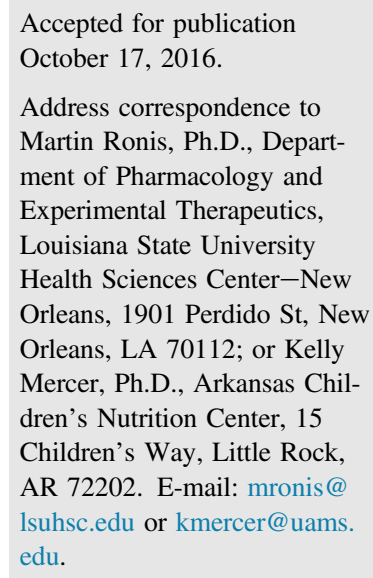

\begin{abstract}
We established a mouse model of developmental nonalcoholic steatohepatitis (NASH) by feeding a high polyunsaturated fat liquid diet to female glutathione-S-transferase 4-4 (Gsta ${ }^{-/-}$)/peroxisome proliferator activated receptor $\alpha\left(\right.$ Ppara $\left.^{-/-}\right)$double knockout $129 / \mathrm{SvJ}$ mice for 12 weeks from weaning. We used it to probe the importance of lipid peroxidation in progression of NASH beyond simple steatosis. Feeding $\mathrm{Gsta}^{-/-} / \mathrm{Ppara}^{-/-}$double-knockout ( $\mathrm{dKO}$ ) mice liquid diets containing corn oil resulted in a percentage fat-dependent increase in steatosis and necroinflammatory injury $(P<0.05)$. Increasing fat to $70 \%$ from $35 \%$ resulted in increases in formation of 4-hydroxynonenal protein adducts accompanied by evidence of stellate cell activation, matrix remodeling, and fibrosis $(P<0.05)$. Comparison of $d K O$ mice with wild-type $(\mathrm{Wt})$ and single knockout mice revealed additive effects of $\mathrm{Gsta}^{-/-}$and Ppara ${ }^{-/}$silencing on steatosis, 4-hydroxynonenal adduct formation, oxidative stress, serum alanine amino transferase, expression of tumor necrosis factor alpha, Il6, interferon mRNA, and liver pathology $(P<0.05)$. Induction of Cyp2e1 protein by high-fat diet was suppressed in $\mathrm{Gsta4}^{-/-}$and $d K O$ groups $(P<0.05)$. The $d K O$ mice had similar levels of markers of stellate cell activation and matrix remodeling as $P_{p a r a}{ }^{--}$single $\mathrm{KO}$ mice. These data suggest that lipid peroxidation products play a role in progression of liver injury to steatohepatitis in NASH produced by high-fat feeding during development but appear less important in development of fibrosis. (Am J Pathol 2017, 187: 418-430; http://dx.doi.org/10.1016/j.ajpath.2016.10.022)
\end{abstract}

Pediatric nonalcoholic fatty liver disease is a prevalent chronic liver pathology observed in $9.6 \%$ of children and up to $38 \%$ of those that are obese. ${ }^{1}$ Fatty liver disease has been reported in morbidly obese children as young as 2 to 3 years old. $^{1,2}$ In approximately $30 \%$ of cases, pediatric liver pathology progresses from simple steatosis to nonalcoholic steatohepatitis (pNASH), characterized by necroinflammation and development of fibrosis. ${ }^{3}$ pNASH is now the major cause of liver transplant in pediatric populations. ${ }^{4}$ However, despite the emergence of pNASH as a major pediatric disease, little is known regarding the molecular mechanisms underlying the development of NASH in children and there are no good developmental animal models that mimic the natural etiological setting in which pNASH develops clinically.

A nutritional model of adult NASH was developed in Sprague-Dawley rats by Lieber et $\mathrm{al}^{5}{ }^{5}$ in which liver pathology developed after feeding a $71 \%$ high-fat liquid diet. This high-fat feeding model was also applied to adult mice lacking the transcription factor peroxisome

\footnotetext{
Supported by NIH/National Institute on Alcohol Abuse and Alcoholism grant R37AA009300 (D.P.) and by US Department of Agriculture, Agricultural Service Current Information System, grant 6251-51000-010-05S.

M.R. and K.M. contributed equally to this work as first authors.

Disclosures: None declared.
} 
Table 1 Real-Time RT-PCR Primer Sequences

\begin{tabular}{|c|c|c|}
\hline Gene & Forward sequence & Reverse sequence \\
\hline \multicolumn{3}{|c|}{ Fatty acid homeostasis } \\
\hline Fatp2 & 5'-CGGGAGAGCAAACTACCTACA-3' & $5^{\prime}$-АACCTCACСTTTGGGGACT-3' \\
\hline Fasn & $5^{\prime}-\mathrm{TGACCTCGTGATGAACGTGTAC-3^{ \prime }}$ & $5^{\prime}$-GGGTGAGGACGTTTACAAAGG-3' \\
\hline Cyp $4 a 10$ & $5^{\prime}$-CCCTGATGGACGCTCTTTAC-3' & 5'-GGGTCAAACACCTCTGGATT-3' \\
\hline Cyp $4 a 14$ & $5^{\prime}$-GCCAGGAACTGCATTGGGAAACA-3' & $5^{\prime}-$ TTTGGACTTCAGCACAAATCGGGC- $3^{\prime}$ \\
\hline Pparg & $5^{\prime}$-CACAATGCCATCAGGTTTGG-3' & 5'-GCTGGTCGATATCAGTGGAGATC-3' \\
\hline Plin2 & $5^{\prime}$-ATTGCGGTTGCCAATACCTATGCC-3' & $5^{\prime}$-TCGGACGTTGGCTGGTTCAGAATA-3' \\
\hline$A p o B$ & $5^{\prime}$-ATACCACGTTTGCAAGCAGAAGCC-3' & $5^{\prime}$-TGTTGAGCCGTAAGCTGTAGCAGA-3' \\
\hline \multicolumn{3}{|c|}{ ROS generation } \\
\hline Cyp2e1 & 5'-AACAGAGACCAGCACAACTCT-3' & 5'-TCTCATGCACTACAGCGTCCATGT-3' \\
\hline Nox2 & 5'-GGGATGAATCTCAGGCCAAT-3' & 5'-GCCGTCCATACAGAGTCTTC-3' \\
\hline Tnfa & $5^{\prime}$-GACGTGGAACTGGCAGAAGAG-3' & $5^{\prime}-$ GCCACAAGCAGGAATGAGAAG- $3^{\prime}$ \\
\hline Il6 & $5^{\prime}$-CTTCACAAGTCGGAGGCTTAAT-3' & 5'-GCAAGTGCATCATCGTTGTTC-3' \\
\hline Cd14 & $5^{\prime}$-CTAAGTATTGCCCAAGCACACTCA-3' & 5'-CCCAACTCAGGGTTGTCAGACA-3' \\
\hline Cd68 & 5'-TTCTCCAGCTGTTCACCTTGACCT-3' & 5'-GTTGCAAGAGAAACATGGCCCGAA-3' \\
\hline $\mathrm{Cd} 4$ & $5^{\prime}-\mathrm{TCCCACTCACCCTCAAGATA-3^{ \prime }}$ & $5^{\prime}$-ATAACCACCAGGTTCACTTC-3' \\
\hline$B 220$ & 5'-СССТTCTTCTGCCTCAAAGT-3' & 5'-CACCTGGATGATATGTGGTCTC-3' \\
\hline Cd138 & $5^{\prime}$-ATGCGTACAACAGGGTATGG- $3^{\prime}$ & 5'-GAGGTGGCTATTCCACAGTATC-3' \\
\hline \multicolumn{3}{|c|}{ Stellate cell activation, matrix remodeling, and fibrosis } \\
\hline $\operatorname{Tgfb}$ & 5'-CTGCGGCAGCTGTACATTGACTTT-3' & 5'-TGTACTGTGTGTCCAGGCTCCAAA- $3^{\prime}$ \\
\hline Col1a1 & $5^{\prime}$-AGGCTTTGATGGACGCAATG-3' & $5^{\prime}$-GCGGCTCCAGGAAGACC $-3^{\prime}$ \\
\hline Pdgfrb & $5^{\prime}$-CCTCGGCCTGTGACTAGAAG-3' & $5^{\prime}-$ GGACGAGGGGAACAACATTA- $3^{\prime}$ \\
\hline
\end{tabular}

ROS, reactive oxygen species.

proliferator receptor $\alpha\left(\right.$ Ppara $\left.^{-1-}\right)$, a member of the nuclear receptor superfamily that is essential for lipid metabolism via mitochondrial and peroxisomal $\beta$ - and $\omega$-oxidation pathways. $^{6}$ It was shown that this knockout resulted in enhanced steatosis, lipid peroxidation, and inflammation compared to wild-type (Wt) mice fed highfat liquid diets for 3 weeks. ${ }^{7}$ More recently, we have made mice with a double knockout of $\mathrm{Ppara}^{-1-}$ and the glutathione-S-transferase enzyme $\mathrm{Gsta}^{-1-}(\mathrm{dKO}){ }^{8}{ }^{8}$
Gsta4 is a detoxification enzyme that eliminates reactive electrophilic $\alpha, \beta$ unsaturated aldehydes, such as the lipid peroxidation product 4-hydroxynonenal (4-Hne). ${ }^{9}$ We demonstrated that these $d K O$ mice had enhanced hepatic Hne protein adducts, circulating autoantibodies against lipid peroxidation product-adducted proteins, necroinflammatory injury, stellate cell activation, and matrix remodeling than either wild-type mice or mice with knockout of either gene alone when fed chronically

Table 2 Effects of High-Fat Feeding on Nonfibrotic Liver Pathology in Ppara ${ }^{-/-} /$Gsta4 $^{-/-}$Double-Knockout Female Mice Receiving a 35\% or $70 \%$ Fat Liquid Diet or Chow Fed from Weaning to Adulthood

\begin{tabular}{llllllll}
\hline & \multicolumn{2}{l}{ Pathology score } & & \multicolumn{2}{c}{ TNF- $\alpha$ mRNA } \\
\cline { 2 - 4 } Group & Steatosis & Inflammation/necrosis & Total & Serum ALT (U/L) & expression & Liver weight (g) & Liver triglycerides (g) \\
\hline Chow & $0.2 \pm 0.20$ & $0.1 \pm 0.08$ & $0.3 \pm 0.18$ & $27.6 \pm 0.60$ & $1.0 \pm 0.33$ & $0.72 \pm 0.05$ & $17.2 \pm 2.6$ \\
$35 \%$ fat & $2.4 \pm 0.24^{*}$ & $2.1 \pm 0.81^{*}$ & $4.5 \pm 1.00^{*}$ & $46.7 \pm 11.1^{*}$ & $3.6 \pm 1.04^{*}$ & $0.79 \pm 0.04$ & $40.3 \pm 1.5$ \\
$70 \%$ fat & $2.7 \pm 0.18^{*}$ & $2.5 \pm 0.32^{*}$ & $5.2 \pm 0.2^{*}$ & $90.4 \pm 13.7^{* \dagger}$ & $5.7 \pm 0.73^{* \dagger}$ & $0.97 \pm 0.03^{* \dagger}$ & $111.0 \pm 2.5^{* \dagger}$ \\
\hline
\end{tabular}

Data are expressed as means \pm SEM. Total liver pathology was assessed in hematoxylin and eosin-stained sections by a veterinary pathologist, as described in Materials and Methods. Serum ALT values were determined as described in Materials and Methods. Triglyceride concentrations were biochemically measured, as previously described. ${ }^{16}$ Statistical significance for the effects associated by increasing fat intake in the diet was determined by one-way analysis of variance, followed by Student-Newman-Keuls post hoc analysis. $n=7$ animals per liquid diet group; $n=5$ animals per chow group.

${ }^{*} P<0.05$ versus chow.

${ }^{\dagger} P<0.05$ versus $35 \%$ high-fat diet.

ALT, alanine aminotransferase; TNF- $\alpha$, tumor necrosis factor- $\alpha$. 

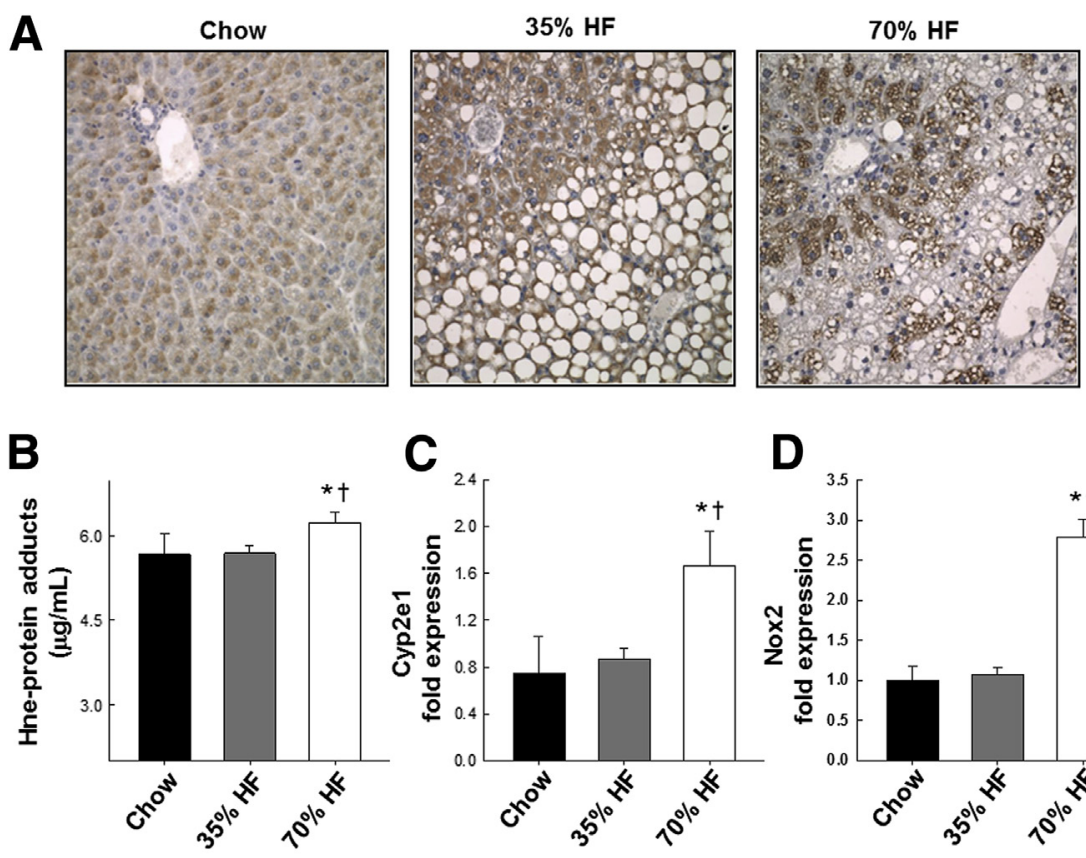

C
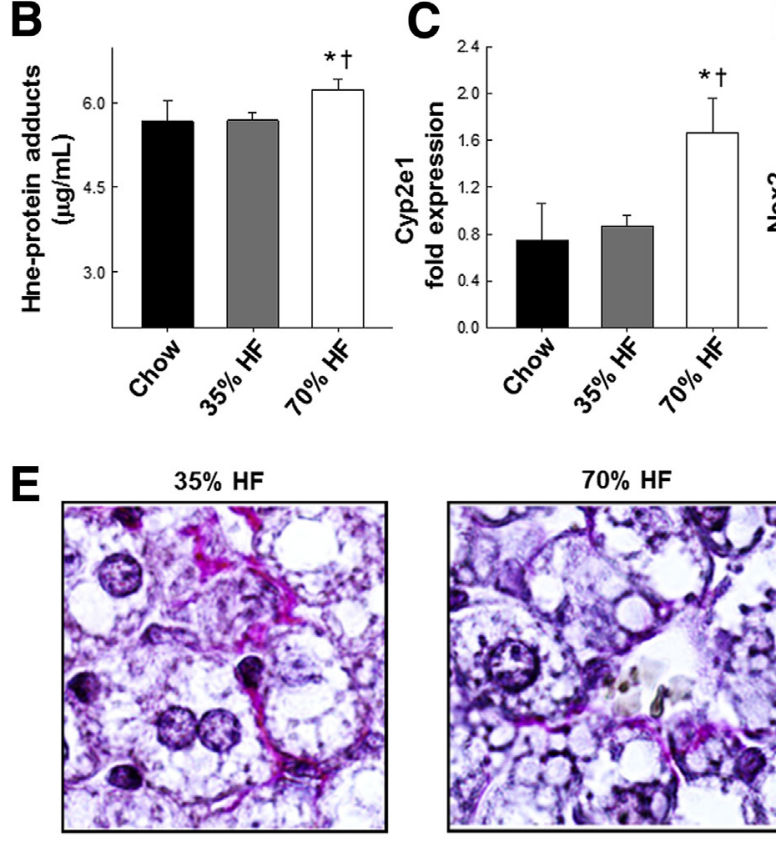

D
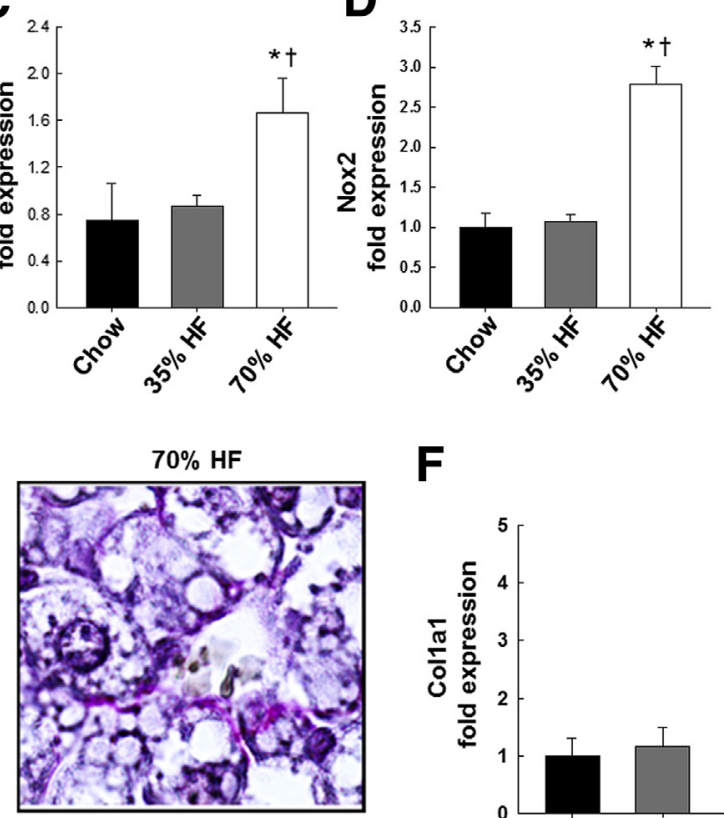

$\mathbf{F}$

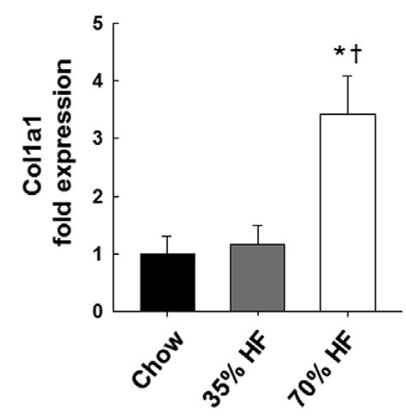

Figure 1 Lipid peroxidation product adducts; reactive oxygen species generation; and markers of stellate cell activation, fibrosis, and matrix remodeling in livers of Ppara ${ }^{-/} / \mathrm{gsta4}^{-/-}$double knockout (dKO) mice fed chow, $35 \%$, or $70 \%$ polyunsaturated fat (HF) diets. A: Representative immunohistochemistry of 4-hydroxynonenal (4Hne) adducts in liver sections. B: Quantification of Hne protein adducts. C: Cyp2e1 mRNA expression. D: Nox2 mRNA expression. E: Representative sections of picrosirius red staining of collagen in HF livers (oil immersion objective). F: $\alpha$ Collagen (Col1a1) mRNA expression. G: Platelet-derived growth factor receptor b (Pdgfrb) mRNA expression. Statistical significance was determined by one-way analysis of variance followed by StudentNewman-Keuls post hoc analysis. Data are expressed as means \pm SEM (B-D, F, and $\mathbf{G}) . n=$ 5 mice (chow); $n=7$ mice ( $35 \%$ or $75 \% \mathrm{HF}$ ). ${ }^{*} P<0.05$ for chow versus HF diet; ${ }^{\dagger} P<0.05$ for $35 \%$ HF diet versus $70 \%$ HF diet. Original magnification, $\times 100(\mathbf{E})$. Nox, NADPH oxidase. with alcohol liquid diets. ${ }^{8}$ These data suggested the importance of lipid peroxidation products in progression of alcoholic liver disease and implicated a possible role for autoimmune responses triggered by adducted proteins in this process. Recent studies by Sutti et $\mathrm{al}^{10}$ suggest a similar autoimmune process related to generation of reactive lipid peroxidation products may underlie development of inflammation in NASH. In the current study, we used these $d K O$ mice to establish a developmental model of NASH produced as a result of feeding high polyunsaturated fat diets beginning in early development and to examine the role of lipid peroxidation in progression of liver pathology in mice fed these diets.

\section{Materials and Methods}

\section{Animals and Experimental Design}

All of the animal studies described below were approved by the Institutional Animal Care and Use Committee at the University of Arkansas for Medical Sciences. All animals received humane care according to the criteria outlined in the Guide for the Care and Use of Laboratory Animals ${ }^{11}$ at an American Association for Accreditation of Laboratory Animal Care-approved animal facility at the University of Arkansas for Medical Sciences. Sv $129 / \mathrm{J}$ mice and 129S4/SvJae-Ppara ${ }^{\text {tmlGonz } / J ~(s t o c k ~ n u m b e r ~ 003580) ~ w e r e ~}$ purchased from Jackson Laboratories (Bar Harbor, ME). $\mathrm{Gsta4}^{-1-}$ mice were generated as previously described. ${ }^{12}$ $d K O$ mice were generated by breeding the single knockout strains to produce offspring heterozygous for both genes and subsequent breeding of the $F_{1}$ generation, as previously described. ${ }^{8}$ In experiment 1 , to establish a developmental NASH model, female $d K O$ mice were weaned onto standard rodent chow $(n=5)$, onto liquid diets containing 35\% energy from polyunsaturated fat (corn oil), $18 \%$ from protein (casein), and $47 \%$ from carbohydrates (dextrose/maltodextrin, $4: 1)$ (35\% fat) $(n=7)$ or liquid diets containing $70 \%$ energy from polyunsaturated fat, $18 \%$ from protein, and $12 \%$ from carbohydrate ( $70 \%$ fat) $(n=7)$ and fed ad libitum for 12 weeks. Vitamin and mineral composition was based on $\mathrm{Na}$ tional Research Council recommendations for growing 
Table 3 Biochemical Analysis of Serum and Hepatic Lipid Concentrations and Liver Pathology in Chow-Fed and $70 \%$ Fed Wt, Gsta4 ${ }^{-1-}$, Ppara $^{-/-}$, and Ppara ${ }^{-/-} /$Gsta4 $^{-/-}$dKO Mice

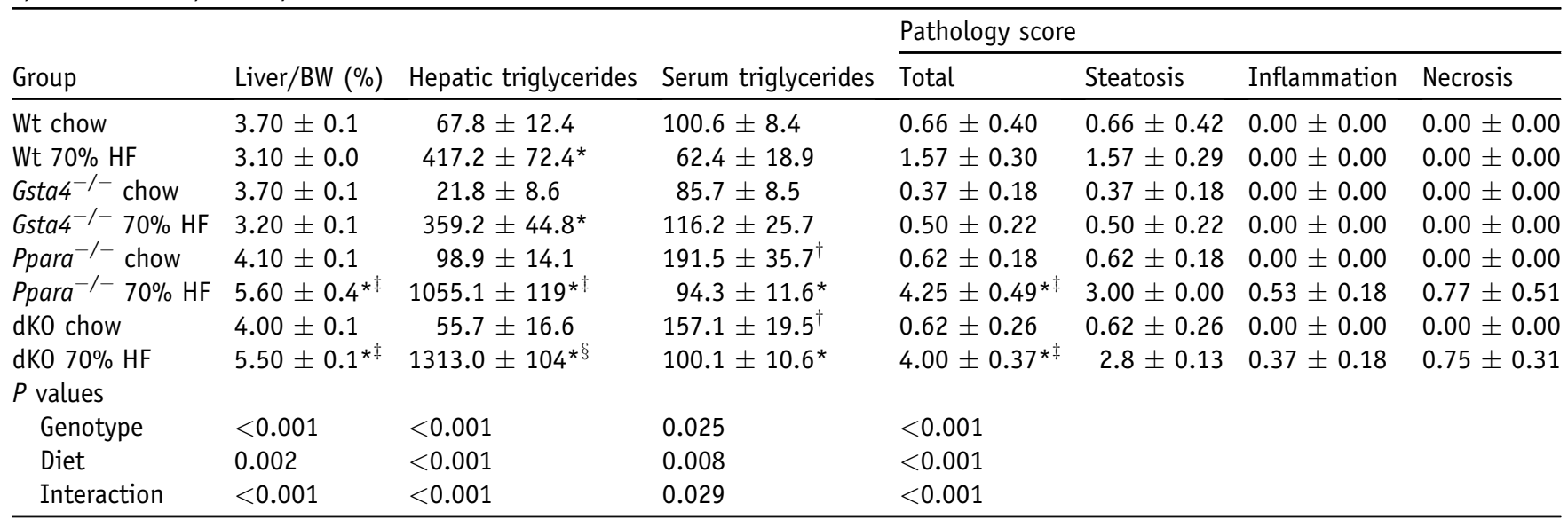

Data are expressed as means \pm SEM. Triglyceride concentrations were biochemically measured, as stated in Materials and Methods. ${ }^{16}$ Total liver pathology was assessed in hematoxylin and eosin-stained sections by a veterinary pathologist, as described in Materials and Methods. Statistical significance was determined by two-way analysis of variance, followed by Student-Newman-Keuls post hoc analysis. $n=6$ animals per wild-type group; $n=8$ animals per knockout group.

${ }^{*} P<0.05$ for chow versus $70 \% \mathrm{HF}$ diet (within each genotype).

${ }^{\dagger} P<0.05$ (between genotypes for chow diet).

${ }^{\ddagger} P<0.05$ (between genotypes for $70 \% \mathrm{HF}$ diet).

${ }^{\S} P<0.01$ (between genotypes for $70 \% \mathrm{HF}$ diet).

$B W$, body weight; dKO, double knockout; HF, high fat; Wt, wild type.

mice. ${ }^{13}$ In experiment 2, female $S v 129 \mathrm{Wt}$; $\mathrm{Gsta}^{-1-}$, Ppara $^{-/-}$; and $d K O$ mice ( $n=6$ to 8 per group) were weaned onto standard rodent chow or $70 \%$ fat liquid diets and fed ad libitum for 12 weeks. All groups in both experiments had ad libitum access to water. Animal body weights were measured weekly. At sacrifice, serum was collected, liver was weighed, and pieces were formalin fixed and frozen for further analysis. Serum alanine aminotransferase levels were assessed as a measure of liver damage by using the Infinity alanine aminotransferase liquid stable reagent (Thermo Electron, Waltham, MA), as per manufacturer's instructions. Accumulation of hepatic lipid droplets was measured by quantitation of oil red $\mathrm{O}$ staining. ${ }^{8,14}$ In addition, triglycerides were extracted from serum and liver homogenates with chloroform/methanol $(2: 1, \mathrm{v} / \mathrm{v})$, and triglyceride concentrations were assayed using commercially available reagents (Cayman Chemical, Ann Arbor, MI). Overall hepatic oxidative stress was also assessed by measuring oxidized and reduced glutathione concentrations (reduced glutathione/ oxidized glutathione) using a kit from Cayman Chemical.

\section{Lipid Peroxidation}

Liver 4-Hne adducts were detected immunohistochemically and quantified, as previously described by Shearn et al. ${ }^{15}$ Immunohistochemical characterization was performed using rabbit polyclonal anti-4-Hne and goat anti-rabbit polyclonal antibodies Vectastain ABC IHC kit (Vector Labs, Burlingame, CA). Images were taken on a NIKON Eclipse TE300 (Nikon Instruments Inc., Melville, NY) at $\times 100$ magnification using a DS-Fi2 camera (Nikon Instruments Inc.). Quantification was done using NIS Elements version 4.13.04 (Nikon Instruments Inc.) and three measurements per zone (centrilobular or periportal), four exposures per slide, and four animals per condition. Exposure time was 24 milliseconds, and the area of measurement was $100 \times 100$ pixels. Overall changes in staining were quantified by using the ratio of staining in the periportal region compared to the centrilobular region (zone 1/zone 3). The pathological significance of hepatocellular inflammation was assessed using immunohistochemistry and antibodies directed against CD3 (goat anti-rabbit polyclonal; Dako, Carpinteria, CA), B220 (rat-anti-mouse polyclonal; BD Biosciences, San Jose, CA), and F4/80 (rat-anti-mouse polyclonal; ABD Serotec Biorad, Hercules, CA). Colocalization studies were performed in liver sections from $\mathrm{dKO}$ mice to determine whether 4-Hne adducts occurred in Kupffer cells or stellate cells in addition to hepatocytes. Serial sections were stained for 4HNE, F4/80, or the appearance of $\alpha$-smooth muscle actin (Sigma, St. Louis, MO) (a marker of activated stellate cells).

\section{Liver Pathology}

Liver samples were fixed in $10 \%$ neutral buffered formalin and processed, and paraffin-embedded sections were stained with hematoxylin and eosin. Hematoxylin and eosin-stained liver sections were scored for steatosis, inflammation (macrophage infiltration), and necrosis by a veterinary pathologist (L.H.) with no prior knowledge of the treatment groups. Steatosis was scored as the percentage of parenchymal cells containing fat (microsteatosis or macrosteatosis) as $<5 \%$ indicates $0 ; 5 \%$ to $33 \%, 1 ;>33 \%$ to $66 \%, 2$; and $>66 \%, 3 .{ }^{14}$ Presence of contiguous patches of microsteatosis 
A

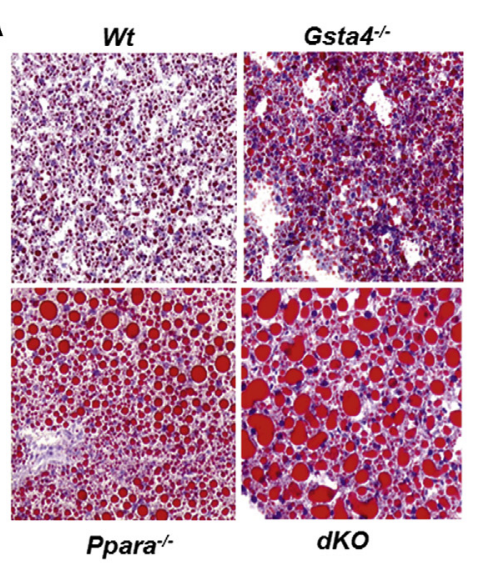

Ppara $^{-/}$

D

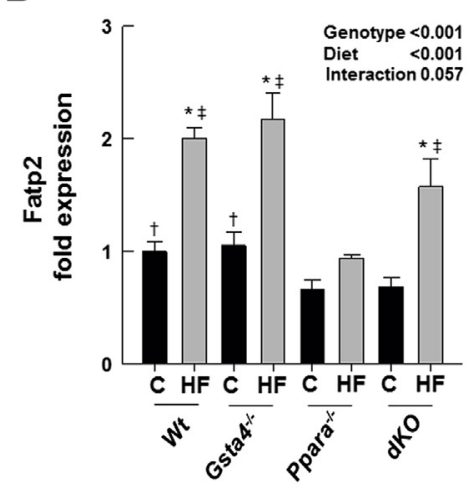

G

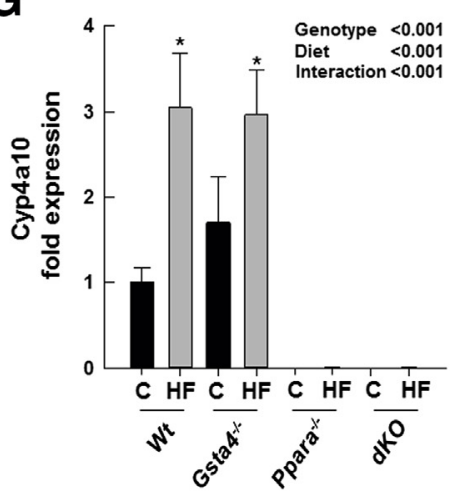

B

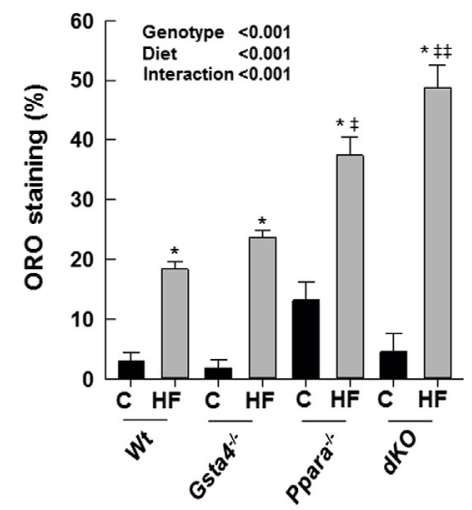

E

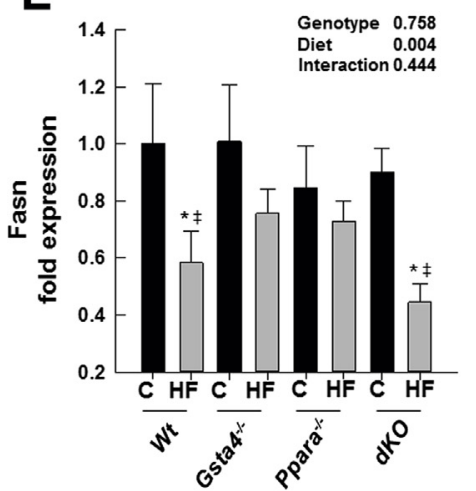

H

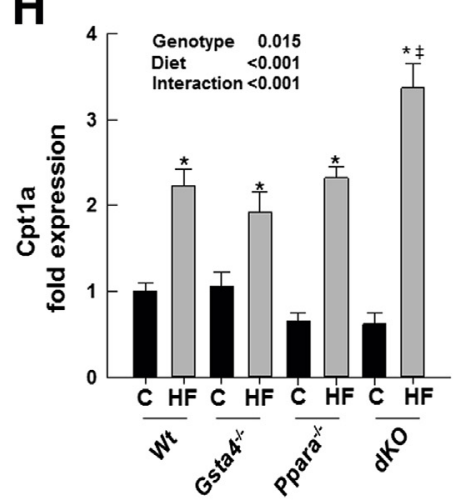

C

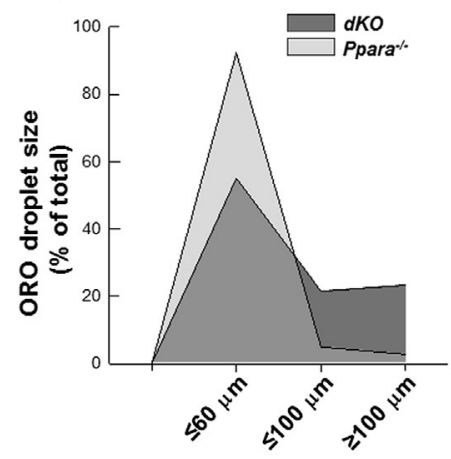

F

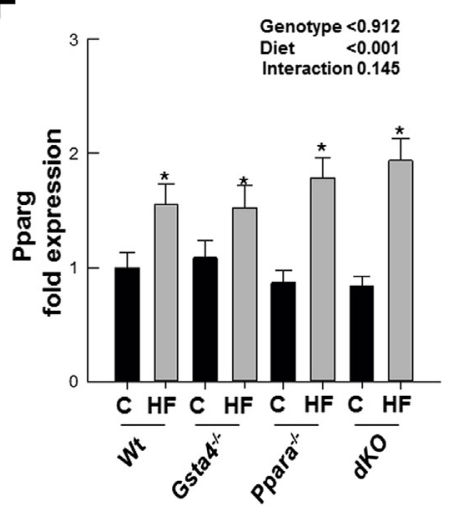

I

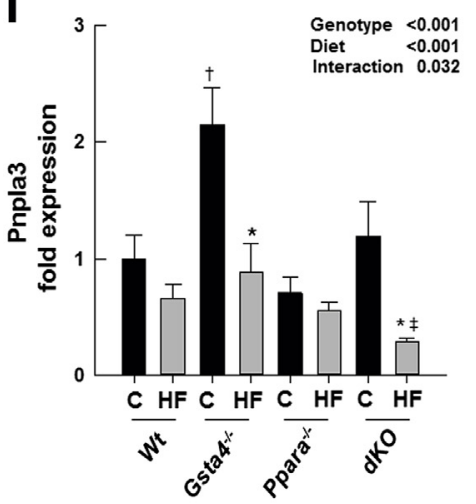

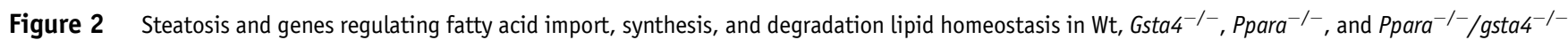
double-knockout $(d K O)$ mice fed chow or $70 \%$ polyunsaturated fat (HF) diets. A: Representative sections of oil red 0 (ORO) -stained lipid droplets in HF livers. B: Quantitation of ORO staining. C: Distribution of lipid droplet size in Ppara ${ }^{-/-}$and Ppara ${ }^{-1-} / \mathrm{gsta}^{-/-}$double-knockout (dKO) mice fed HF diets. D: Fatty acid transport protein (Fatp2) mRNA expression. E: Fatty acid synthase (Fasn) mRNA expression. F: Peroxisome proliferation-activated receptor $\gamma$ (Pparg) mRNA expression. G: Cyp4a10 mRNA expression. H: Carnitine palmitoyltransferase (Cpt1) mRNA expression. I: Patatin-like phospholipase domain containing 3 (Pnpla3) mRNA expression. Statistical significance was determined by two-way analysis of variance, followed by Student-Newman-Keuls post hoc analysis. Data are expressed as means \pm SEM (B and $\mathbf{D}-\mathbf{I}$ ). $n=6$ to 8 per group (B and $\mathbf{D}-\mathbf{I}) .{ }^{*} P<0.05$ for chow $(C)$ versus $70 \%$ HF diet (within each genotype); ${ }^{\dagger} P<0.05$ (between genotypes for chow diet); ${ }^{\ddagger} P<0.05,{ }^{\ddagger \ddagger} P<0.01$ (between genotypes for $70 \% \mathrm{HF}$ diet). Original magnification, $\times 20$ (A).

was given a weighted score of 1 . The presence of inflammation based on infiltration by polymorphonuclear cells, leukocytes, and mononuclear cells was evaluated using a scale where no inflammation indicates $0 ;<2$ foci of inflammatory cells per $\times 200$ field, 1 ; 2 to 4 foci per $\times 200$ field, 2 ; and $>4$ foci per $\times 200$ field, 3 . For scoring of necrosis, the presence of necrotic foci was assessed using a scale where
0 indcates none; 1 , few; and 2, many. ${ }^{14}$ Fibrosis was detected histologically by picrosirius red staining of collagen. ${ }^{8}$

\section{Gene Expression and Western Blotting}

Expression of mRNAs coding for genes involved in oxidative stress, lipid homeostasis, inflammation and 
A
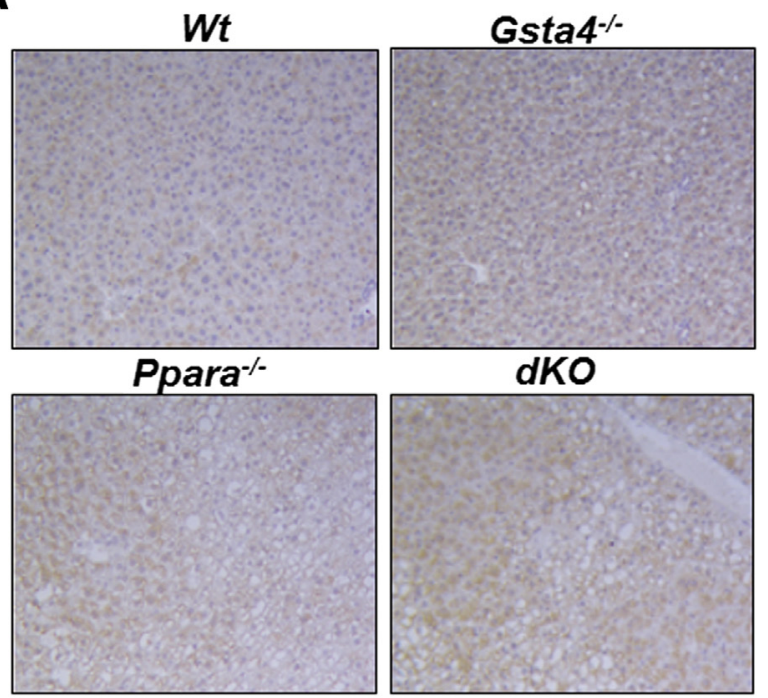

B

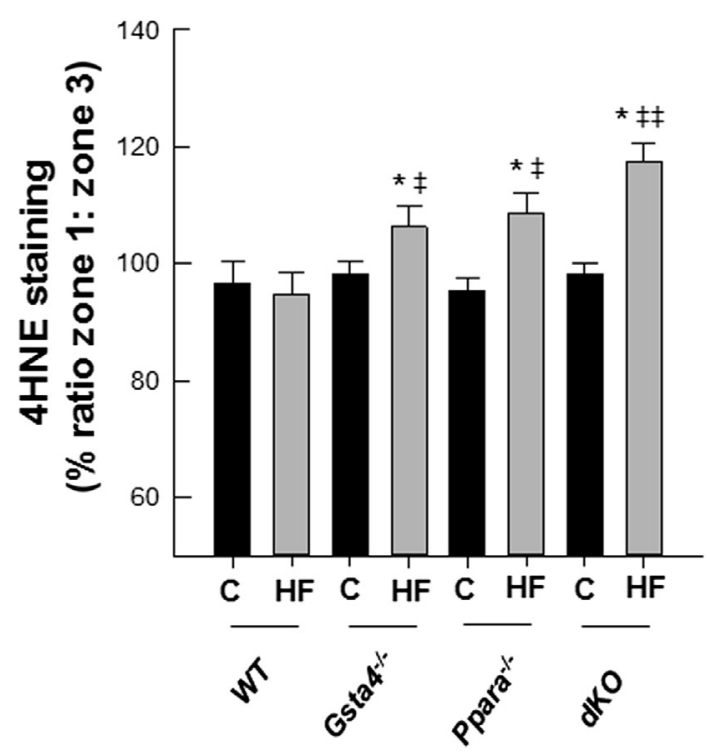

Figure 3 A: Representative 4-hydroxynonenal (4-Hne) adduct staining in livers of Wt, Gsta4 ${ }^{-1-}$, Ppara $^{-/-}$, and Ppara ${ }^{-/} /$gsta4 $^{-/-}$doubleknockout $(d K O)$ mice fed $70 \%$ polyunsaturated fat (HF) diets. B: Ratio of zone 1 /zone 3 staining. Statistical analysis was determined by two-way analysis of variance, followed by Student-Newman-Keuls post hoc analysis. Data are expressed as means \pm SEM (B). $n=6$ to 8 per group (B). ${ }^{\star} P<0.05$ for chow (C) versus $70 \% \mathrm{HF}$ diet (within each genotype); ${ }^{\ddagger} P<0.05,{ }^{\ddagger \ddagger} P<0.01$ (between genotypes for $70 \% \mathrm{HF}$ diet).

macrophage infiltration, immune cell subclasses, matrix remodeling, and fibrosis were assessed by real-time RTPCR. Briefly, total RNA was isolated from liver using Tri reagent (MRC, Cincinnati, OH), as per manufacturer's protocol, and reversed transcribed using iScript cDNA synthesis kit (Bio-Rad Laboratories, Hercules, CA). Gene expression was determined by use of SYBR Green and an ABI 7500 sequence detection system (Applied Biosystems, Foster City, CA). Results were quantified using $\Delta \mathrm{Ct}$ method relative to glyceraldehyde-3-phosphate dehydrogenase, and then to Wt controls. Gene-specific primers are presented in
Table 1. Livers from experiment 2 were also analyzed for Cyp2e1 and Cyp4a apoprotein expression by Western immunoblot using polyclonal antibodies against rat Cyp2e1 and Cyp4a, which cross-react with their mouse homologues, as previously described. ${ }^{14}$ Protein bands were quantified using a densitometer, and band densities were corrected for total protein loaded by staining the membrane with $0.1 \%$ amido black.

\section{Statistical Analysis}

Data are presented as means \pm SEM. In experiment 1 , the effect of increasing dietary fat content in $d K O$ mice was determined by one-way analysis of variance, followed by Student-Newman-Keuls post hoc analysis. In experiment 2, the Wt, Gsta4 ${ }^{-1-}$, Ppara $^{-/-}$, and $d K O$ genotype, of chow and $70 \%$ fat groups and the interaction thereof were determined using a four- by two-way analysis of variance, followed by Student-Newman-Keuls post hoc analysis. Statistical significance was set at $P<0.05$. SigmaPlot software package version 11.0 (Systat Software, Inc., San Jose, CA) was used to perform all statistical tests.

\section{Results}

Development of pNASH in dK0 Mice Fed $70 \%$ Polyunsaturated Fat during Early Development

In experiment 1, 12 weeks of high-fat feeding had a significant impact on weight gain compared to chow controls, $20.28 \pm 0.64 \mathrm{~g}$ and $20.14 \pm 0.50 \mathrm{~g}$ for $35 \%$ fat group and $70 \%$ fat group, respectively, versus $17.6 \pm 0.92 \mathrm{~g}$ in the chow controls $(P<0.05)$. We observed no difference in body weight between $d K O$ fed mice at $35 \%$ or $70 \%$ fat. Hepatic steatosis was evident in both the $35 \%$ and $70 \%$ fat groups compared to chow-fed $d K O$ mice $(P<0.05)$, and biochemical analysis of triglyceride content revealed a doubling in the $35 \%$ fat group and a sixfold increase in the $70 \%$ fat group compared to chow feeding $(P<0.05)$ (Table 2). Liver weight, as a percentage of body weight, was also significantly increased in the $70 \%$ fat compared to other groups $(P<0.05)$. As seen in Figure $1 \mathrm{~A}$, the pattern of steatosis was primarily centrilobular macrosteatosis, in some cases extending out to the portal triad. Around the portal triad, the steatosis that was evident was primarily microsteatosis. In addition to steatosis, necroinflammatory injury developed in $d K O$ mice fed both liquid polyunsaturated fat diets. Pathology scores were elevated in both the $35 \%$ and $70 \%$ fat groups compared to chow-fed $d K O$ mice $(P<0.05)$ (Table 2). In addition, a fat concentration-dependent increase was observed in serum alanine amino transferase activities (a biochemical marker of hepatic necrosis) and in expression of the proinflammatory cytokine tumor necrosis factor mRNA $(P<0.05)$ (Table 2$)$. In the $70 \%$ fat group, significant increases in expression of mRNAs encoding reactive oxygen species-generating enzymes Cyp2e1 and 
Table 4 Biochemical and Molecular Evaluation of Oxidative Stress and Liver Inflammation and Necrosis in Wt, Gsta4 ${ }^{-/-}$, Ppara ${ }^{-/-}$, and Ppara $^{-/-} /$Gsta4 $^{-/-}$dKO Mice Receiving a Chow or 70\% HF Diet

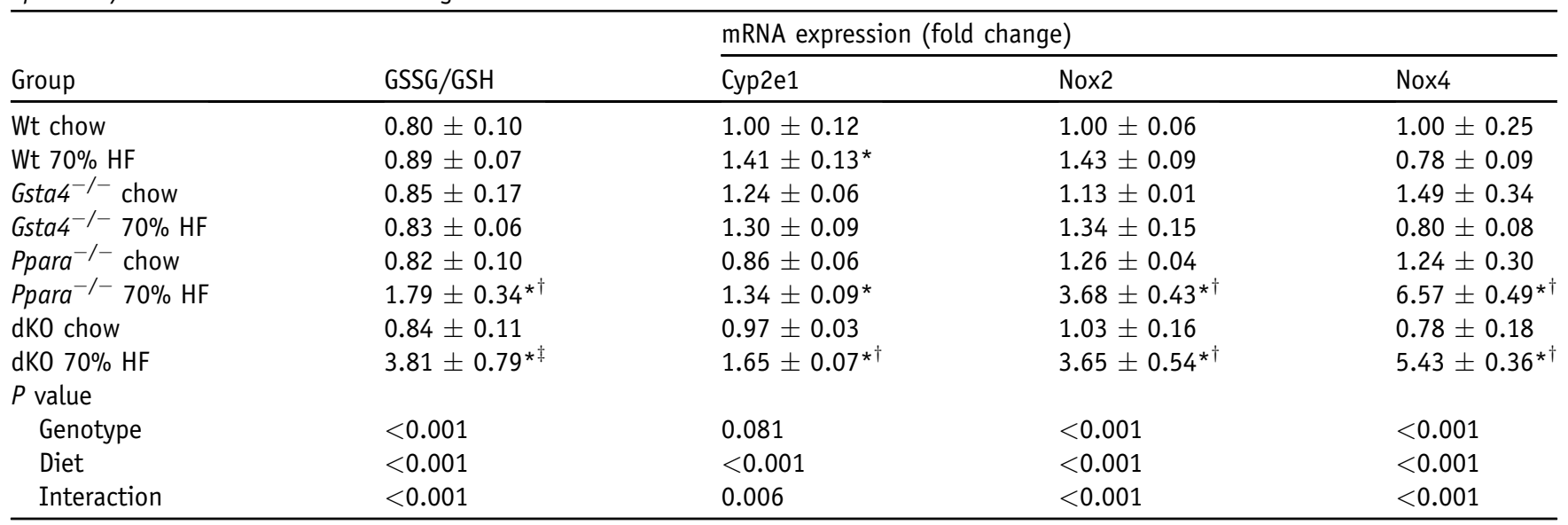

Data are expressed as means \pm SEM. Hepatic GSSG/GSH ratio was determined as stated in Materials and Methods. Gene expression was assessed by real-time RT-PCR using $2^{-\Delta \Delta C T}$ method, as described in Materials and Methods. Statistical analysis was performed by two-way analysis of variance, followed by StudentNewman-Keuls post hoc analysis. $n=6$ animals per wild-type group; $n=8$ animals per knockout group.

${ }^{*} P<0.05$ for chow versus $70 \% \mathrm{HF}$ diet (within each genotype).

${ }^{\dagger} P<0.05$ (between genotypes for $70 \%$ HF diet).

${ }^{\ddagger} P<0.01$ (between genotypes for $70 \% \mathrm{HF}$ diet).

dKO, double knockout; GSH, reduced glutathione; GSSG, oxidized glutathione; HF, high fat; Nox, NADPH oxidase; Wt, wild type.

NADPH oxidase (Nox)2 relative to chow or $35 \%$ fat-fed mice $(P<0.05)$ was accompanied by higher expression of periportal 4-Hne protein adducts detected by immunohistochemistry $(P<0.05)$ (Figure $1, A-D)$. In Figure 1E, picrosirius red staining of livers revealed areas in which collagen fibers appeared to form networks surrounding individual steatotic parenchymal cells in both $35 \%$ and $70 \%$ fat fed groups of mice that were absent in the chow group (data not shown). Although extensive fibrosis was not evident in any treatment group, the $70 \%$ fat group did display evidence of increased stellate cell activation compared to the $35 \%$ fat or chow-fed groups: increased expression of platelet-derived growth factor receptor b mRNA was observed accompanied by increased expression of $\alpha$ collagen mRNA $(P<0.05)$ (Figure $1, \mathrm{~F}$ and $\mathrm{G})$.

\section{Effect of Ppara ${ }^{-/-}$and Gsta4 ${ }^{-/-}$Genotype Alone or} Together on Liver Pathology after Chronic Feeding of Diets High in Polyunsaturated Fat

To distinguish the effects of ablation of $\mathrm{Ppara}^{-1-}$ versus $\mathrm{Gsta4}^{-1-}$ on NASH development in this model and determine the role reactive electrophilic $\alpha, \beta$ unsaturated aldehyde products of lipid peroxidation on liver pathology, we conducted a second experiment. Female Wt mice and female mice with knockout of one gene were compared with $d K O$ mice in the developmental high-fat feeding model. In experiment 2 , no significant group differences in weight gain, which ranged from 20 to $22 \mathrm{~g}$, were associated with 12 weeks' feeding of the $70 \%$ fat diet from weaning. Liver weight, as a percentage of body weight, was elevated relative to chow-fed mice in both the $70 \%$ fat Ppara $^{-1-}$ and the $d K O$ groups compared to the Wt and $\mathrm{Gsta4}^{-1-}$ mice $(P<0.05)$ (Table 3). Liver triglyceride concentrations determined biochemically were elevated by $70 \%$ fat diets compared to chow-fed mice in all groups. However, liver triglyceride concentrations were greater in the $70 \%$ fat $\mathrm{Ppara}^{-1-}$ group compared to Wt or $\mathrm{Gsta4}^{-1-}$ groups $(P<0.05)$ and higher in the $70 \%$ fat $d K O$ group than any other group $(P<0.05)$. Increased liver triglycerides were accompanied by significant reductions in serum triglyceride levels in both the Ppara $^{-1-}$ and $d K O$ groups $(P<0.05)$ (Table 3$)$. Examination of the appearance of hepatic lipid droplets by oil red $\mathrm{O}$ staining revealed a similar pattern to biochemical measures of triglyceride content, with a higher level of droplets in $70 \%$ fat $d K O$ mice compared to either single knockout group (Figure 2, A and B). Moreover, the size of the lipid droplets was significantly greater in the $70 \%$ fat $d K O$ mice compared to single KOs (Figure 2C). Pathological examination revealed the presence of inflammatory infiltrates and necrotic foci in both the $70 \%$ high-fat (HF) $\mathrm{Ppara}^{-/-}$and $d K O$ groups but not in the Wt or $G_{s t a 4^{-/-}}$groups. Overall liver pathology was higher in the $70 \% \mathrm{HF}$ Para $^{-1-}$ group than $70 \% \mathrm{HF}$ Wt or Gsta $^{-/-}$mice and was even more pronounced in the $70 \%$ HF $d K O$ mice (Table 3).

\section{Effect of Ppara ${ }^{-/-}$and Gsta4 ${ }^{-/-}$Genotype Alone or} Together on Hepatic Lipid Homeostasis after Chronic Feeding of Diets High in Polyunsaturated Fat

To determine the effects of the $\mathrm{Gsta4}^{-/-}$and $\mathrm{Ppara}^{-/-}$genotype on lipid homeostasis after feeding of high polyunsaturated fat diets, we examined mRNA expression of genes involved in fatty acid uptake (fatty acid transport 

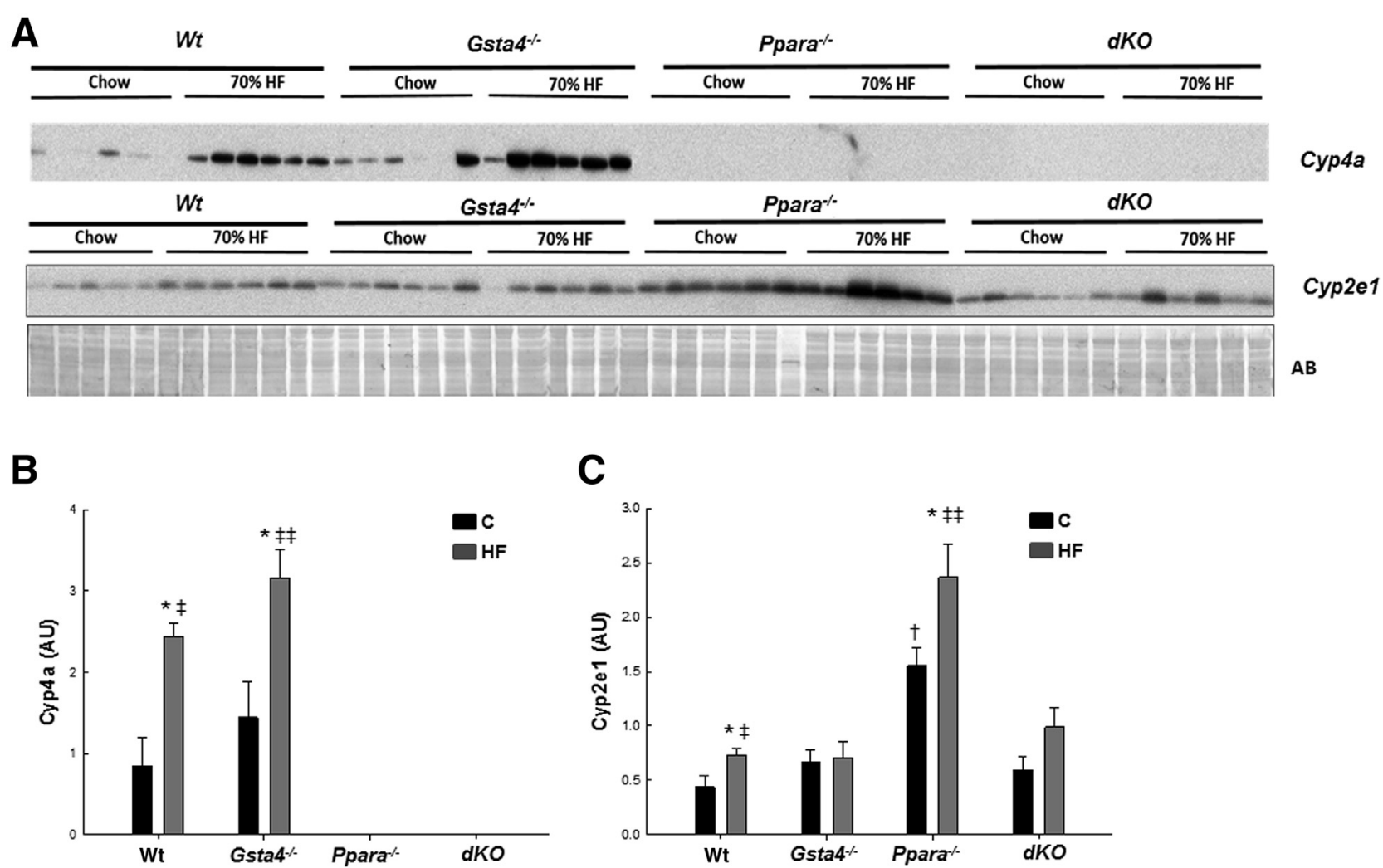

Figure 4 A: Western immunoblot analysis of Cyp4a and Cyp2e1 expression in livers of Wt, Gsta4 ${ }^{-/-}$, Ppara ${ }^{-/-}$, and Gsta4 ${ }^{-/-} /$Ppara $^{-/-}$double-knockout $(d K 0)$ mice fed chow or $70 \%$ polyunsaturated fat (HF) diets. Each lane contains samples from a single mouse. B: Immunoquantification of Cyp4a expression corrected for differences in protein loading. C: Immunoquantification of Cyp2e1 expression corrected for differences in protein loading. Statistical analysis was determined by two-way analysis of variance, followed by Student-Newman-Keuls post hoc analysis. ${ }^{*} P<0.05$ for chow (C) versus $70 \%$ HF diet (within each genotype); ${ }^{\dagger} P<0.05$ (between genotypes for chow diet); ${ }^{\ddagger} P<0.05,{ }^{\ddagger \ddagger} P<0.01$ (between genotypes for $70 \% \mathrm{HF}$ diet). AB, amido black staining of total protein.

protein), fatty acid synthesis (fatty acid synthase and peroxisome proliferator-activated receptor $\gamma$ ), fatty acid degradation [cytochrome P450 Cyp4a10 (Cyp4a10) and carnitine palmitoyltransferase], triglyceride mobilization from lipid droplets (patatin-like phospholipase domain containing 3), and with very-low-density lipoprotein formation (apolipoprotein B100). As seen in Figure 2D, fatty acid transport protein expression in both chow-fed and high fat-fed mice was significantly lower in $\mathrm{Ppara}^{-1-}$ and $d K O$ mice than in Wt or $\mathrm{Gsta4}^{-1-}$ mice $(P<0.05)$. Feeding of $70 \% \mathrm{HF}$ diets increased expression of fatty acid transport protein mRNA in all genotypes, except Ppara $^{-1-}$ mice, relative to feeding chow $(P<0.05)$. In contrast, no effects of genotype were observed on expression of fatty acid synthase mRNA in chow-fed mice, but the significant suppression of fatty acid synthase mRNA expression observed in 70\% HF fed Wt and $d K O$ mice relative to chow-fed controls was not observed in either 70\% HF-fed $\mathrm{Gsta4}^{-1-}$ or Ppara ${ }^{-1-}$ mice (Figure 2E). Peroxisome proliferator-activated receptor $\gamma$ expression increased significantly after HF feeding irrespective of genotype (Figure 2F). Expression of the Ppara ${ }^{-1-}$ target gene Cyp4a10, which catalyzes the $\omega$-hydroxylation of fatty acids, was absent, as expected, from livers of $\mathrm{Ppara}^{-1-}$ and $d \mathrm{KO}$ mice. In Wt and $\mathrm{Gsta}^{-1-}$ mice, feeding of $70 \% \mathrm{HF}$ diets significantly increased Cyp4a10 mRNA expression $(P<0.05)$. Expression of mRNA encoding carnitine palmitoyltransferase, which is responsible for the rate-limiting transport of fatty acids into the mitochondria for degradation via $\beta$-oxidation, was significantly increased in $70 \% \mathrm{HF}-$ fed groups of all genotypes relative to chow feeding $(P<0.05)$ and expression was higher in $70 \%$ HF-fed $d K O$ mice than in mice with single knockdown of either gene $(P<0.05)$ (Figure $2, \mathrm{G}$ and $\mathrm{H})$. Expression of mRNA encoding patatin-like phospholipase domain containing 3 was reduced relative to chow-fed controls by $70 \% \mathrm{HF}$ feeding only in $\mathrm{Gsta4}^{-1-}$ and $d K O$ mice $(P<0.05)$ (Figure 2I). No statistically significant effects of diet or genotype were observed on apolipoprotein B100 mRNA expression (data not shown).

Effect of Ppara ${ }^{-/-} \alpha$ and Gsta4 ${ }^{-/-}$Genotype Alone or Together on Hepatic 0xidative Stress and Necroinflammation after Chronic Feeding of Diets High in Polyunsaturated Fat

In Figure 3, increases in lipid accumulation and liver pathology were accompanied by increased appearance of periportal 4-Hne protein adducts in liver slices in $70 \%$ 
Table 5 Effects of a 70\% HF Diet on Hepatic Immune Cell Response in Wt, Gsta4 ${ }^{-/-}$, Ppara ${ }^{-/-}$, and Ppara ${ }^{-/} /$Gsta4 $^{-/-}$Female Mice

\begin{tabular}{|c|c|c|c|c|}
\hline \multirow[b]{2}{*}{ Group } & \multirow[b]{2}{*}{ Serum ALT (U/L) } & \multicolumn{3}{|c|}{ mRNA expression (fold change) } \\
\hline & & Tnfa & Il6 & Cd14 \\
\hline Wt chow & $32.39 \pm 8.66$ & $1.00 \pm 0.15$ & $1.00 \pm 0.14$ & $1.00 \pm 0.17$ \\
\hline Gsta4 $^{-/-}$chow & $24.18 \pm 2.64$ & $0.95 \pm 0.12$ & $1.29 \pm 0.18$ & $1.47 \pm 0.15$ \\
\hline Gsta4 $^{-/-} 70 \% \mathrm{HF}$ & $52.21 \pm 9.32^{* \dagger}$ & $2.62 \pm 1.05$ & $0.80 \pm 0.07$ & $0.75 \pm 0.05$ \\
\hline Ppara $^{-/-}$chow & $30.17 \pm 4.38$ & $1.61 \pm 0.50$ & $1.57 \pm 0.21$ & $1.48 \pm 0.10$ \\
\hline$d K O \quad 70 \% \mathrm{HF}$ & $67.71 \pm 5.86^{\star \ddagger}$ & $8.33 \pm 0.79^{\star \ddagger}$ & $4.59 \pm 1.83^{* \dagger}$ & $3.90 \pm 0.73^{* \dagger}$ \\
\hline \multicolumn{5}{|l|}{$P$ value } \\
\hline Genotype & 0.049 & $<0.001$ & 0.025 & $<0.001$ \\
\hline Diet & 0.003 & $<0.001$ & 0.337 & $<0.001$ \\
\hline Interaction & 0.553 & $<0.001$ & 0.080 & $\begin{array}{c}<0.001 \\
\text { (table continues) }\end{array}$ \\
\hline
\end{tabular}

Data are expressed as means \pm SEM. Gene expression expressed as fold change relative to the Wt control group, as described in Materials and Methods. Statistical analysis was performed by two-way analysis of variance, followed by Student-Newman-Keuls post hoc analysis. $n=6$ animals per wild-type groups; $n=8$ animals per knockout groups.

${ }^{*} P<0.05$ for chow versus $70 \% \mathrm{HF}$ diet (within each genotype).

$\dagger P<0.05$ (between genotypes for $70 \% \mathrm{HF}$ diet).

$\ddagger P<0.01$ (between genotypes for $70 \% \mathrm{HF}$ diet).

ALT, alanine aminotransferase; dKO, double knockout; HF, high fat; Ifng, interferon; Tnfa, tumor necrosis factor; Wt, wild type.

fat-fed mice relative to chow-fed mice in both $G s t a 4^{-1-}$ and Ppara $^{-1-}$ mice compared to the Wt group $(P<0.05)$ and by the highest level of adducts in the $70 \%$ fat $d K O$ group $(P<0.05)$. No significant effects of genotype or diet were observed on expression of mRNA encoding aldehyde dehydrogenase 2, which, in addition to Gsta4, is the other major enzyme involved in detoxification of 4-Hne (data not shown). Coincident with increased protein carbonylation, we observed increases in the oxidized glutathione/reduced glutathione ratio in the $70 \%$ fat Ppara $^{-1-}$ and $d K O$ groups relative to the $\mathrm{Gsta4}^{-1-}$ and Wt groups $(P<0.05)$, indicative of increased oxidative stress (Table 3). Cyp2e1 mRNA was increased $(P<0.05)$ by feeding $70 \% \mathrm{HF}$ diets in all genotypes, except Gsta4 $^{-1-}$ mice (Table 4). In contrast, at the level of protein expression, two-way analysis of variance indicated genotype diet interaction $(P<0.05)$. Cyp2e1 was higher in Ppara $^{-1-}$ mice compared to Wt controls, but induction of Cyp2E1 after feeding 70\% HF diets was not observed in either the $\mathrm{Gsta}^{-1-}$ or $d K O$ groups (Figure 4). Cyp4a apoprotein expression was increased by $70 \% \mathrm{HF}$ diets in both Wt and Gsta4 $^{-1-}$ mice $(P<0.05)$, but no expression was observed in either Ppara ${ }^{-1-}$ or $d K O$ groups (Figure 4). Nox2 and Nox4 mRNAs were increased compared to chow-fed controls in both Ppara $^{-/-}$and $d K O$ mice $(P<0.05)$ (Table 4). Increased oxidative stress in $70 \%$ HF-fed Ppara $^{-1-}$ and $d K O$ groups was accompanied by evidence of increased inflammation and necrosis. Interestingly, proinflammatory cytokines, tumor necrosis factor $\alpha$, interferon $\gamma$, and Il6, mRNAs were significantly up-regulated in $70 \%$ HF-fed dKO group, and accompanied increased serum alanine aminotransferase values $(P<0.05)$ compared to the HF-fed Ppara ${ }^{--}$, Gsta4 ${ }^{-1-}$, and Wt groups (Table 5). Similarly, increased expression of mRNA encoding B-cell marker B220 was also up-regulated in the $70 \%$ HF-fed dKO group compared to all other HF-fed groups $(P<0.05)$. Gene expression of additional immune cell markers, $\mathrm{Cd} 4, \mathrm{Cd} 44$, and $\mathrm{Cd} 14$, respectively, were elevated in both the 70\% HF-fed Ppara $^{-1-}$ and $d K O$ mice relative to chow-fed controls, $70 \%$ HF-fed Wt, and Gsta $^{-1-}$ mice $(P<0.05)$ (Table 5). Consistent with these findings, we observed increased parenchymal accumulation of B220-positive cells and $\mathrm{Cd} 3$-positive $\mathrm{T}$ cells around necrotic foci in the Ppara $^{-1-}$ and $d K O$ groups compared to the Wt and $\mathrm{Gsta4}^{-1-}$ genotypes receiving the HF diet (Figures 5 and 6). However, there were no genotype or dietary effects on expression of the plasma cell marker CD138 in the HF-fed $d K O$ mice compared to $70 \%$ HF-fed Ppara $^{-1-}$ mice.

\section{Effect of Ppara ${ }^{-/-}$and Gsta4 ${ }^{-/-}$Genotype Alone or Together on Stellate Cell Activation, Fibrosis, and Matrix Remodeling after Chronic Feeding of Diets High in Polyunsaturated Fat}

Parenchymal collagen deposition was assessed histologically using Picosirius red staining in chow-fed and HF-fed Wt, Gsta4 $^{-1-}$, Ppara $^{-1-}$, and $d K O$ genotypes. Overall, bridging fibrosis was not observed in any genotype after high-fat feeding (Supplemental Figure S1). However, mRNA expression of profibrotic markers, tumor growth factor $\beta, \alpha$-smooth muscle actin, $\alpha$ collagen, and matrix remodeling enzymes, matrix metalloproteinase 13 and tissue inhibitor of 
Table 5 (continued)

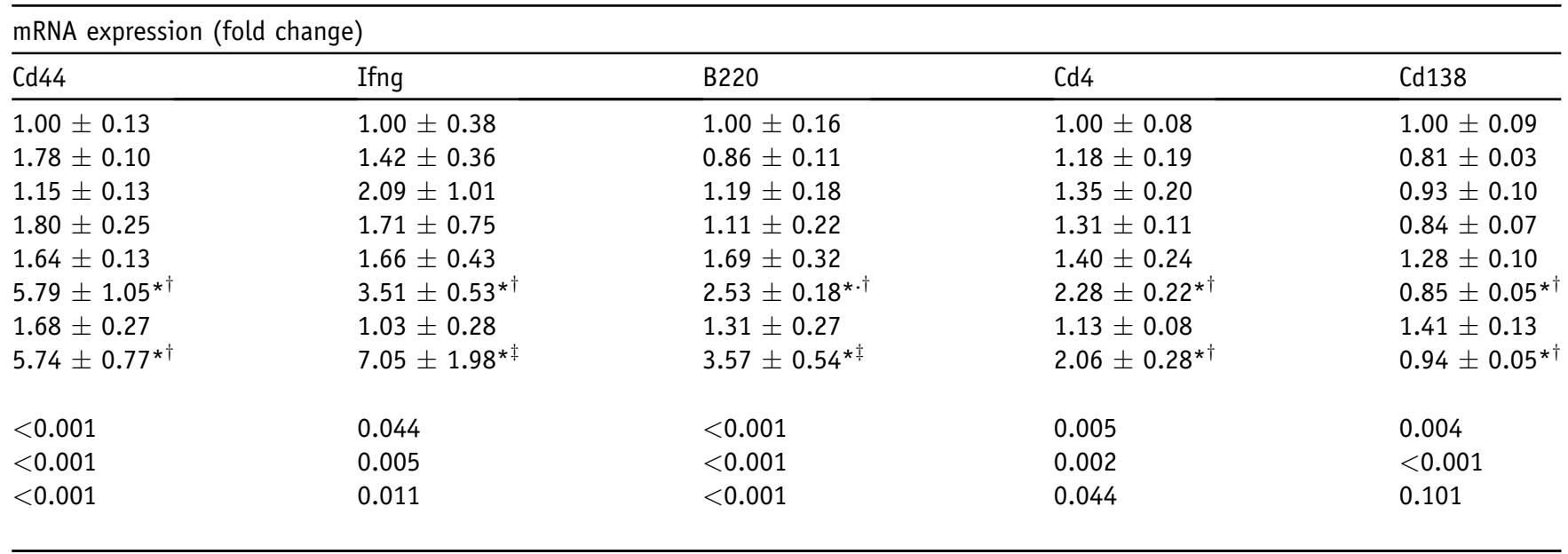

metalloproteinases 1 , were observed after HF feeding in Ppara $^{-1-}$ and $d K O$ mice compared to Wt and $\mathrm{Gsta}^{-1-}$ mice $(P<0.05)$ (Table 6). Consistent with these findings, pericellular picrosirius red staining was observed and $\alpha$-SMA-staining cells were present around necrotic foci in the parenchymal tissue of Ppara $^{-1-}$ and dKO mice receiving 70\% HF diets (Supplemental Figure S2).

\section{Discussion}

In the current study, we used a double-knockout mouse model where Ppara and Gsta4 were deleted to examine the role of steatosis and lipid peroxidation products in the progression of NASH pathology after developmental feeding of high-fat diets. Gsta4 normally contributes in a major manner to detoxification and clearance of $\alpha, \beta$ short chain aldehyde products of lipid peroxidation, such as 4Hne and malondialdehyde. We previously demonstrated that further deletion of Gsta4 in Ppara ${ }^{-l-}$ mice, which are highly prone to development of steatosis, results in increased progression of liver injury to steatohepatitis and fibrosis after chronic alcohol exposure. ${ }^{8}$ Experimental models of clinical pediatric NASH have proved difficult to produce in rodents given the slow development of this pathology relative to the short period between weaning and adulthood in rats and mice and the rapid growth rates of these animals during this period. ${ }^{15,17}$ Because Ppara $^{-1-}$ mice have previously been shown to also have increased steatosis and inflammation in a high-fat liquid diet feeding model of adult NASH, we took a similar approach to develop a new model of developmental
NASH by feeding Ppara $^{-1-} /$ Gsta4 $^{-1-}$ dKO mice liquid diets high in polyunsaturated fat (corn oil, rich in linoleic acid) from weaning to early adulthood. ${ }^{15,17} \mathrm{We}$ observed a fat dose-dependent increase in progression of liver pathology from steatosis to steatohepatitis, stellate cell activation, and initial stages of fibrosis in both Para $^{-1-}$ and $d K O$ mice, consistent with the predicted role for both steatosis and lipid peroxidation products in development of NASH pathology and similar to the dose-responses to overfeeding of polyunsaturated fat diets we have previously reported in adult rat models of NASH. ${ }^{15}$ Pediatric $\mathrm{NASH}$, as observed clinically in children, comes in two histological subtypes: type 1 is characterized by ballooning degeneration of hepatocytes, ${ }^{18}$ macrovesicular steatosis, polymorphonuclear leukocyte infiltration, and perisinusoidal fibrosis; type 2 is associated with steatosis, periportal inflammation, and periportal fibrosis but no ballooning degeneration. The mouse pathology observed in this developmental study more resembles type 1 pNASH rather than type 2 .

To dissect the roles of increased steatosis and lipid peroxidation products in development of NASH in this model, we compared the effects of developmental feeding of $70 \%$ HF diets in wild-type and single knockout mice in comparison with $d K O$ mice. As expected, there was a substantial increase in steatosis in $\mathrm{Ppara}^{-/-}$and $d \mathrm{KO}$ mice, consistent with the pivotal role $\mathrm{Ppara}^{-1-}$ dependent signaling plays in fatty acid degradation. ${ }^{6}$ In addition, the observed decreased expression of fatty acid transport protein and Cyp4a10 mRNAs in chow-fed Ppara $^{-l-}$ and $d K O$ mice is consistent with their being known Ppara target genes. ${ }^{6}$ Interestingly, knockout of Gsta4 resulted in additional accumulation of 


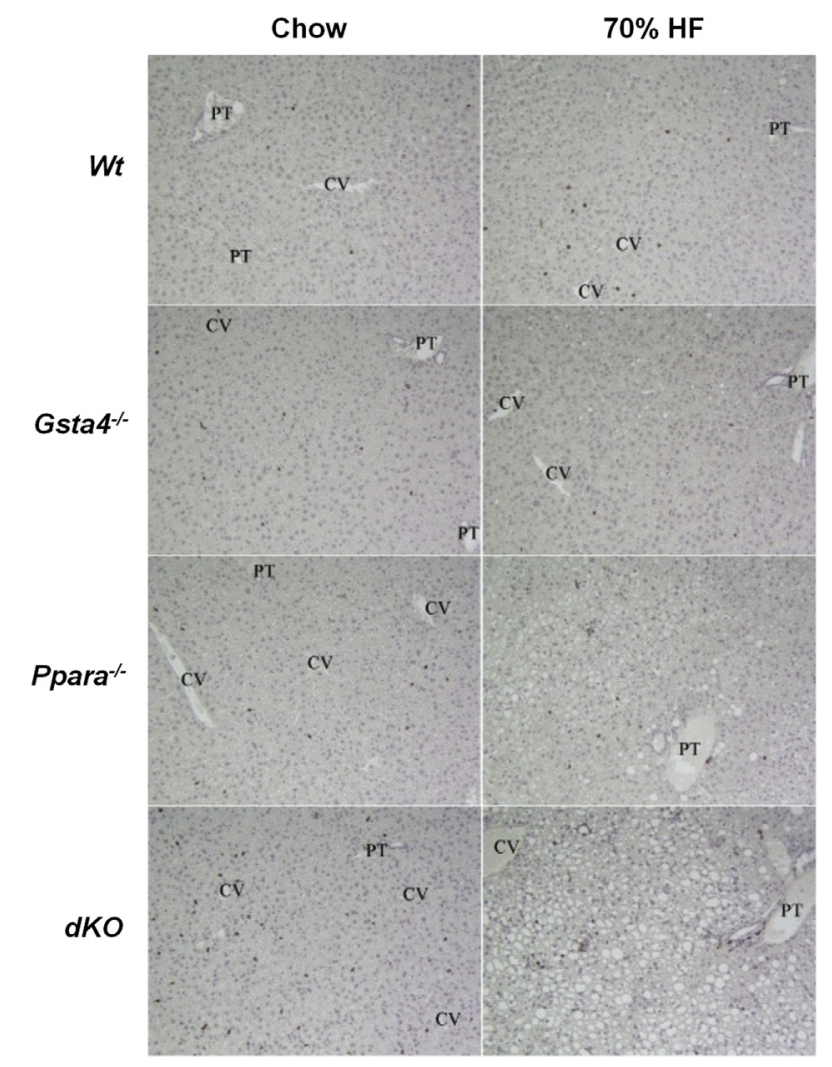

Figure 5 Immunohistochemical staining of B220-positive B cells in representative hematoxylin and eosin liver sections from Wt, $\mathrm{Gsta4}^{-1-}$, Ppara $^{-/}$, and double-knockout ( $d K O$ ) mice receiving either chow or $70 \%$ HF diets for 12 weeks. Immunhohistochemistry was performed as described in Materials and Methods. CV, central vein; PT, portal triad.

triglycerides and fat droplets in 70\% HF-fed $d K O$ compared to $70 \% \mathrm{HF}-f e d \mathrm{Ppara}^{-/-}$mice. Moreover, the lipid droplets in the $d K O$ mice were significantly larger. We have reported similar increases in steatosis in mice with $\mathrm{Gsta}^{-/-}$and dKO genotypes compared to Wt and Ppara $^{-1-}$ mice fed chronically with ethanol. ${ }^{8}$ The current data are consistent with the suggested role of lipid peroxidation in disruption of fatty acid homeostasis leading to enhanced lipid accumulation. ${ }^{8,12}$ We have previously reported an age-dependent increase in obesity in chow-fed Ssta $^{-1-}$ mice on the $126 / \mathrm{SvJ}$ background associated with increases in hepatic and adipose tissue fatty acid synthesis related to increased expression and allosteric activation of acetyl-CoA carboxylase secondary to inhibition of aconitase and increased concentrations of the fatty acid precursor malonyl-CoA. ${ }^{12}$ In addition, it appears that loss of Gsta4 results in disruption of triglyceride mobilization from lipid droplets. Expression of patatin-like phospholipase domain containing 3 mRNA was suppressed by feeding of $70 \% \mathrm{HF}$ diets in $\mathrm{Gsta}^{-1-}$ and $d K O$ but not in Wt or Ppara ${ }^{-1-}$ mice. Epidemiological studies of patatin-like phospholipase domain containing 3 have previously demonstrated increased incidence of fatty liver disease and NASH in individuals harboring dysfunctional mutations of this gene. ${ }^{16}$ Finally, there is evidence in the literature that increased oxidative stress and lipid peroxides associated with the hepatic accumulation of $\omega-3$ and $\omega-6$ polyunsaturated fatty acids has post-transcriptional effects resulting in degradation of apolipoprotein B100 protein and inhibition of very-low-density lipoprotein secretion. ${ }^{19-21}$ Reductions of serum triglyceride concentrations coincident with increased hepatic steatosis are consistent with such an effect on Ppara ${ }^{-/-}$and $d K O$ mice.

Deletion of Ppara has previously been shown to result in progression of liver pathology beyond simple steatosis to inflammation and fibrosis in adult mouse models of alcoholic and nonalcoholic liver disease. ${ }^{6,7,22}$ The current data suggest a similar pattern of pathology when high polyunsaturated fat diets are fed to Ppara ${ }^{-/-}$mice beginning during early development. Increased evidence of oxidative stress, as indicated by increased oxidized glutathione/ reduced glutathione ratio and 4-Hne protein adducts, was observed in $\mathrm{Ppara}^{-1-}$ compared to Wt mice fed $70 \% \mathrm{HF}$ diets. The sources of increased reactive oxygen species appear to be increased expression of Cyp2e1 and Nox2 in these mice, although it is unclear if these enzymes are under direct regulation by Ppara or if their induction is secondary to triglyceride accumulation in these animals. Interestingly,

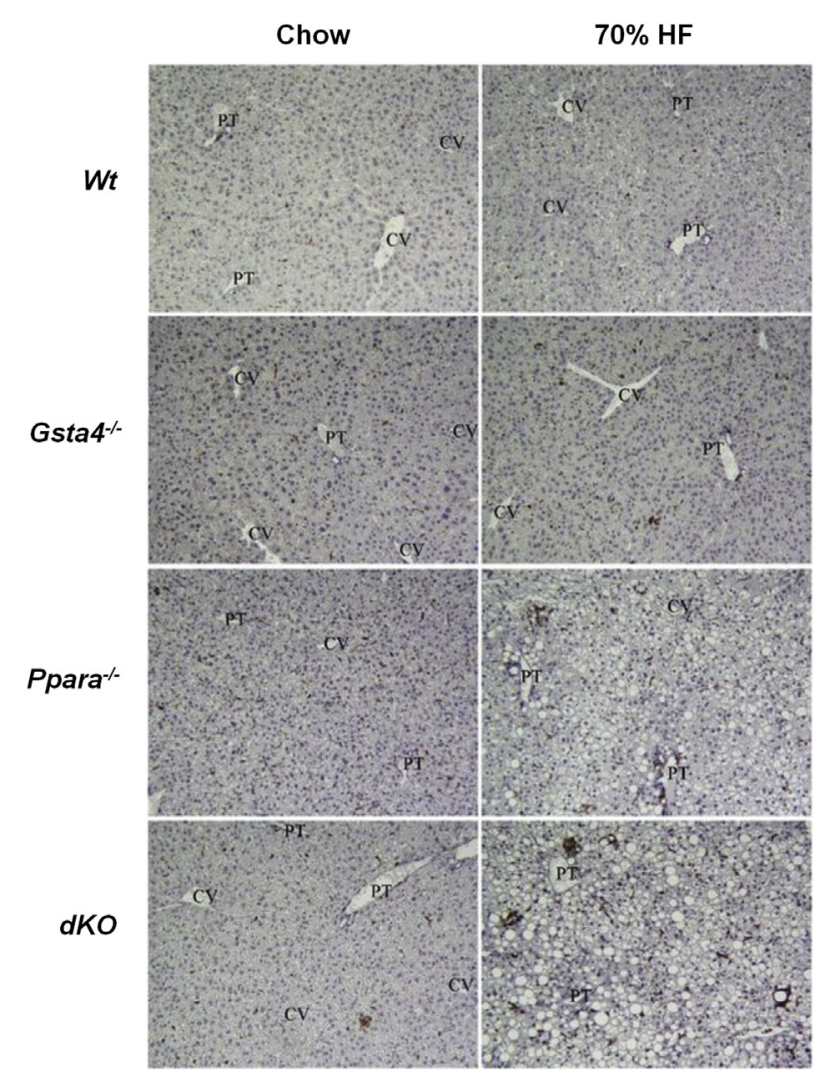

Figure 6 Immunohistochemical staining of Cd3-positive T cells associated with necrotic foci in representative hematoxylin and eosin liver sections from Wt, Gsta4 ${ }^{-/}$, Ppara ${ }^{-/-}$, and $\mathrm{Gsta}^{-/-} / \mathrm{Ppara}^{-/-}$doubleknockout (dKO) mice receiving either chow or $70 \% \mathrm{HF}$ diets for 12 weeks. Immunhohistochemistry was performed as described in Materials and Methods. CV, central vein; PT, portal triad. 
Table 6 Gene Expression of Fibrotic Cytokines and Markers in Livers of Wt, Gsta4 ${ }^{-/}$, Ppara ${ }^{-/}$, and $d K O$ Mice Receiving a Chow or $70 \%$ HF Diet

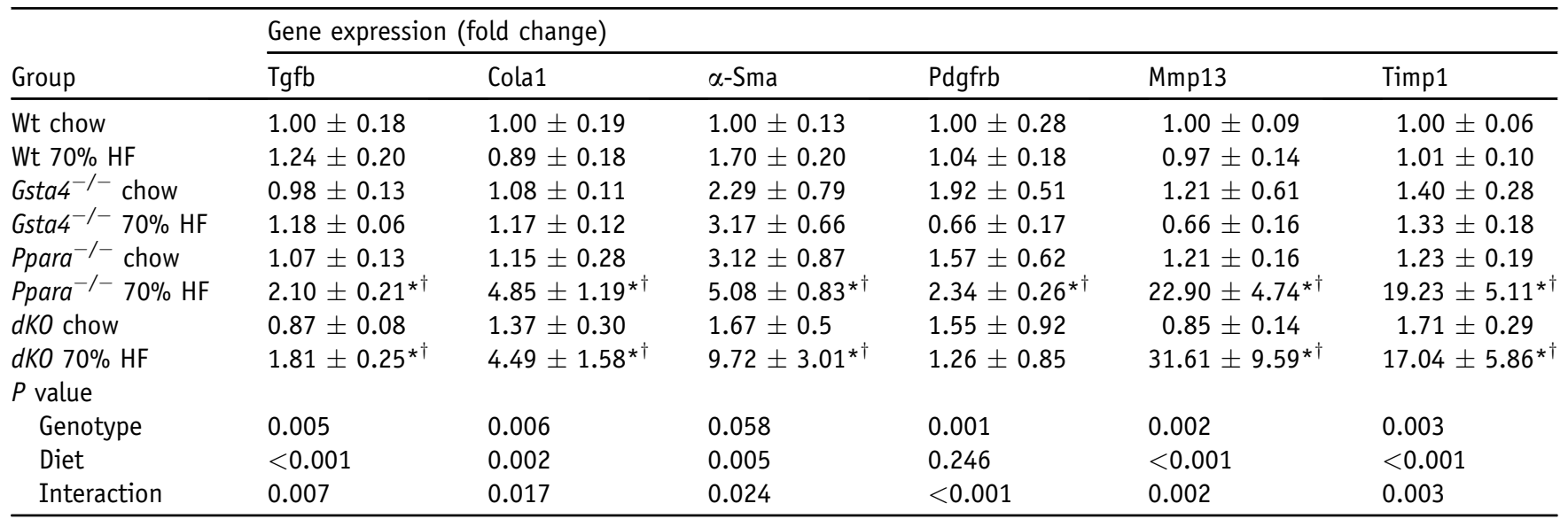

Data are expressed as means \pm SEM. Gene expression as fold change relative to the Wt chow-fed group, as described in Materials and Methods. Statistical analysis was performed by two-way analysis of variance, followed by Student-Newman-Keuls post hoc analysis. $n=6$ animals per Wt groups; $n=8$ animals per knockout groups.

${ }^{*} P<0.05$ for chow versus $70 \% \mathrm{HF}$ diet (within each genotype).

${ }^{\dagger} P<0.05$ (between genotypes for $70 \% \mathrm{HF}$ diet).

Cola1, $\alpha$ collagen; dK0, double knockout; HF, high fat; Mmp, matrix metalloproteinase; Pdgfrb, platelet-derived growth factor receptor b; Tgfb, tumor growth factor $\beta$; Timp, tissue inhibitor of metalloproteinases; Wt, wild type; $\alpha$-Sma, $\alpha$-smooth muscle actin.

the lobular distribution of 4-Hne adducts was shifted toward zone 1 in these mice. Because Cyp2e1 has a centrilobular zone 3 localization, Cyp2e1-derived reactive oxygen species are unlikely to be the major source of 4-Hne. Lobular distribution of Nox enzymes and their potential role in stimulation of lipid peroxidation and progression of hepatic pathology during nonalcoholic fatty liver disease remains the focus of additional research. In this regard, a recent study has linked increased leptin, the essential Nox2 cofactor p47phox, and miR-21 expression with increased tumor growth factor $\beta-$ Smad signaling and fibrosis in adult NASH patients and in adult mice developing NASH after high-fat feeding and treatment with the hepatotoxin bromochloromethane. ${ }^{23}$ Moreover, the presence of $\mathrm{p} 47$ phox in liver parenchymal cells has also been shown to be a key mediator of liver pathology in alcoholic liver disease. ${ }^{24}$ In addition, recent studies from Bettaieb et $\mathrm{al}^{25}$ suggest that hepatocyte Nox4 may also play an important role in development of oxidative stress and progression of NASH pathology to inflammation and fibrosis. In the current study, knockdown of Ppara also resulted in increased inflammation, necrosis, matrix remodeling, and evidence of stellate cell activation and fibrosis after feeding $70 \% \mathrm{HF}$ diets relative to $\mathrm{Wt}$ mice. These data are consistent with previous studies on development of NASH in adult Ppara $^{-1-}$ mice fed high-fat diets ${ }^{7}$ and similar to our previously published data on progression of alcoholic liver pathology in these mice. ${ }^{8}$ Interestingly, and consistent with previous studies of NASH progression in the rat, ${ }^{26} \mathrm{Cd} 44$ mRNA, which encodes the major cell surface hyaluronan (HA) receptor, was significantly up-regulated in $70 \% \mathrm{HF}$ diet-fed Ppara $^{-1-}$ mice. Cd44 plays a role in clearing fragmented HA, which accumulates during tissue injury. ${ }^{27}$ However, HA may also play a role in promoting tissue repair as the result of interactions with Toll-like receptors. In an acute lung injury model, overexpression of high molecular mass HA resulted in protection against injury in part through Toll-like receptor-mediated activation of Nfkb. ${ }^{28}$ It is possible that decreases in HA, as the result of increased Cd44 expression in $70 \%$ HF diet-fed Ppara $^{-1-}$ mice, contributes to the development of fibrosis observed in the current model.

Comparison of $d K O$ mice with Ppara $^{-1-}$ mice revealed significant further increases in oxidative stress, 4-Hne adduct formation, inflammatory cytokine mRNAs encoding tumor necrosis factor, Infg, and Il6, increased B-cell infiltration associated with necrotic foci, and increased evidence of hepatocyte necrosis (alanine aminotransferase values) associated with further increases in overall lipid peroxidation resulting from additional knockout of the $\mathrm{Gsta}^{-1-}$ gene. These data are consistent with a role for lipid peroxidation products in development of necroinflammatory injury and development of autoimmune responses in NASH and with data demonstrating a role of 4-Hne in increased chemotaxis and recruitment of inflammatory cells in response to liver injury. ${ }^{29,30}$ However, in contrast to previous results obtained in this model after adult alcohol treatment, there was no evidence from the current study that increased lipid peroxidation contributes to stellate cell activation, matrix remodeling, or development of fibrosis in pNASH. ${ }^{8}$ These data suggest that, although development of liver pathology is similar in alcoholic and nonalcoholic fatty liver disease, the molecular mechanisms underlying these two conditions are divergent. 


\section{Supplemental Data}

Supplemental material for this article can be found at http://dx.doi.org/10.1016/j.ajpath.2016.10.022.

\section{References}

1. Molleston JP, Schwimmer JB, Yates KP, Murray KF, Cummings OW, Lavine JE, Brunt EM, Scheimann AO, Unalp-Arida A: Histological abnormalities in children with nonalcoholic fatty liver disease and normal or mildly elevated alanine aminotransferase levels. J Pediatr 2014, 164:707-713e3

2. Da Silver GH, Coelho KL, Coelho CA, Escanhoela CA: Mitochondrial alterations in nonalcoholic liver disease: pediatric case description of three submitted sequential biopsies. J Gastrointestin Liver Dis 2009, $18: 215-219$

3. Singer C, Stancu P, Cosoveanu S, Botu A: Non-alcoholic fatty liver disease in children. Curr Health Sci J 2014, 40:170-176

4. Giorgio V, Prono F, Graziano F, Nobili V: Pediatric nonalcoholic liver disease: old and new concepts on development, progression, metabolic insight and potential treatment targets. BMC Pediatr 2013, 13:40

5. Lieber CS, Leo MA, Mak KM, Xu Y, Cao Q, Ren C, Ponomarenko A, DeCarli LM: Model of nonalcoholic steatohepatitis. Am J Clin Nutr 2004, 79:502-509

6. Pawlak M, Lefebvre P, Staels B: Molecular mechanism of Ppara-/- $\alpha$ action and its impact on lipid metabolism, inflammation and fibrosis in non-alcoholic liver disease. J Hepatol 2015, 62:720-733

7. Abdelmegeed MA, Yoo SH, Henderson LE, Gonzalez FJ, Woodcroft KJ, Song BJ: Ppara-/ - $\alpha$ expression protects male mice from high fat-induced nonalcoholic fatty liver. J Nutr 2011, 141:603-610

8. Ronis MJJ, Mercer KE, Gannon B, Engi B, Zimniak P, Shearn CT, Orlicky DJ, Albano E, Badger TM, Petersen DR: Increased 4hydroxynonenal protein adducts in male Gsta4-/-/Ppara-/- $\alpha$ double knockout mice enhance injury during early stages of alcoholic liver disease. Am J Physiol Gastrointest Liver Physiol 2015, 308:G403-G415

9. Balogh LM, Atkins WM: Interactions of glutathione transferases with 4-hydroxynonenal. Drug Metab Rev 2011, 43:165-178

10. Sutti S, Jindal A, Locatelli I, Vacchiano M, Gigliotti L, Bozzola C, Albano E: Adaptive immune response triggered by oxidative stress contribute to hepatic inflammation in NASH. Hepatology 2014, 59: 886-897

11. Committee for the Update of the Guide for the Care and Use of Laboratory Animals; National Research Council: Guide for the Care and Use of Laboratory Animals. ed 8. Washington, DC, National Academies Press, 2011

12. Engle MR, Singh SP, Czernik PJ, Gaddy D, Montague DC, Ceci JD, Yang Y, Awasthi S, Awashi YC, Zimniak P: Physiological role of mGsta4-/-, a glutathione S-transferase metabolizing 4hydroxynonenal: generation and analysis of GSTA4 null mouse. Toxicol Appl Pharmacol 2004, 194:296-308

13. Reeves PG, Niellsen FH, Fahey GC Jr: AIN-93 purified diets for laboratory rodents: final report of the American Institute of Nutrition ad hoc writing committee on the reformulation of the AIN-76A rodent diet. J Nutr 1993, 123:1939-1951

14. Baumgardner JN, Shankar K, Hennings L, Badger TM, Ronis MJJ: A new model for nonalcoholic steatohepatitis in the rat utilizing total enteral nutrition to overfeed a high polyunsaturated fat diet. Am J Physiol Gastrointest Liver Physiol 2008, 294:G27-G38
15. Shearn CT, Smathers RL, Bakos DS, Reigan P, Orlicky DJ, Petersen DR: Increased carbonylation of the lipid phosphatase PTEN contributes to Akt2 activation in a murine model of early alcohol-induced steatosis. Free Radic Biol Med 2013, 65: 680-692

16. He S, McPhaul C, Li JZ, Garuti R, Kinch L, Grishin NV, Cohen JC, Hobbs HH: A sequence variation (I148M) in PNPLA3 associated with nonalcoholic fatty liver disease disrupts triglyceride hydrolysis. J Biol Chem 2010, 285:6706-6715

17. Marecki JC, Ronis MJJ, Badger TM: Ectopic fat disposition and insulin resistance develop after overfeeding of a high fat diet to prepubertal rats despite increased adiponectin signaling. J Nutr Biochem 2011, 22:142-152

18. Manti S, Romano C, Chirico V, Filippelli M, Cuppari C, Loddo I, Salpietro C, Arrigo T: Nonalcoholic fatty liver disease/non-alcoholic steatohepatitis in childhood: endocrine-metabolic "mal-programming". Hepat Mon 2014, 14:e17641

19. Pan M, Cederbaum AI, Zhang YL, Ginsberg HN, Williams KJ, Fisher EA: Lipid peroxidation and oxidant stress regulate hepatic apoplipoprotein B degradation and VLDL production. J Clin Invest 2004, 113:1277-1287

20. Andreo U, Elkind J, Blachford C, Cederbaum AI, Fisher EA: Role of superoxide radical anion in the mechanism of apoB100 degradation induced by DHA in hepatic cells. FASEB J 2011, 25:3554-3560

21. Fisher EA: The degradation of apolipoprotein B100: multiple opportunities to regulate VLDL triglyceride production by different proteolytic pathways. Biochem Biophys Acta 2012, 1821:778-781

22. Nakajima T, Kamio Y, Tanaka N, Sugiyama E, Tanaka E, Kiyosawa K, Fukushima Y, Peters JM, Gonzalez FJ, Aoyama T: Peroxisome proliferator activated receptor alpha protects against alcohol-induced liver damage. Hepatology 2004, 40:972-980

23. Dattaroy D, Pourhoseini S, Das S, Alhasson F, Seth RK, Nagrakatti M, Michelotti GA, Diehl AM, Chatterjee S: Micro-RNA 21 inhibition of SMAD7 enhances fibrogenesis via leptin-mediated NADPH oxidase in experimental and human nonalcoholic steatohepatitis. Am J Physiol Gastrointest Liver Physiol 2015, 308:G298-G312

24. Levin I, Petrasek J, Szabo G: The presence of p47phox in liver parenchymal cells is a key mediator in the pathogenesis of alcoholic liver disease. Alcohol Clin Exp Res 2012, 36:1397-1406

25. Bettaieb A, Jinag JX, Sasaki Y, Chao TI, Kiss Z, Chen X, Tian J, Katsuyama M, Yabe-Nishimura C, Xi Y, Szyndralewiez C, Schroder K, Shah A, Brandes RP, Haj FG, Torok NJ: Hepatocyte nicotinamide adenine dinucleotide phosphate reduced oxidase 4 regulates stress signaling, fibrosis and insulin sensitivity during development of steatohepatitis in mice. Gastroenterology 2015, 149:468-480

26. Baumgardner JN, Shankar K, Hennings L, Albano E, Badger TM, Ronis MJJ: N-acetylcysteine attenuates progression of liver pathology in a rat model of non-alcoholic steatohepatitis. J Nutr 2008, 138: 1872-1879

27. Jiang D, Linag J, Li Y, Noble PW: The role of Toll-like receptors in non-infectious lung injury. Cell Res 2006, 16:693-702

28. Jiang D, Linag J, Noble PW: Hyaluronin in tissue injury and repair Annu Rev Cell Dev Biol 2007, 23:435-461

29. Curzio M: Interactions between neutrophils and 4-hydroxynonenals and consequences on neutrophil motility. Free Radic Res Commun 1988, 5:55-66

30. Rossi MA, Curzio M, DiMauro C, Fidale F, Garramone A, Esterbauer H, Torrelli M, Diazani MU: Experimental studies on the mechanisms of action of 4-hydroxy-2,3-transnonenal, a lipid peroxidation product displaying chemotactic activity towards rat neutrophils. Cell Biochem Funct 1991, 9:163-170 